\title{
Activation process of air stable nanoscale zero-valent iron particles
}

\author{
D Ribas ${ }^{1,2}$, M Černík ${ }^{3}$, J Benito ${ }^{4}$ J. Filip ${ }^{5}$ and V Marti ${ }^{1,2}$ \\ ${ }^{1}$ Fundació CTM Centre Tecnològic (CTM), Pl. de la ciència, 2, 08243 Manresa, Spain. \\ 2 Department of Chemical Engineering, Technical University of Catalonia (UPC), ETSEIB, Av. \\ Diagonal, 647, 08028, Barcelona, Spain. \\ ${ }^{3}$ Institute for Nanomaterials, Advanced Technologies and Innovation, Technical University of Liberec, \\ Studentská 1402/2, 46117 Liberec 1, Czech Republic. \\ ${ }^{4}$ Department of Materials Science and Metallurgy Engineering, Technical University of Catalonia \\ (UPC), EUETIB, Comte d'Urgell, 187, 08036, Barcelona, Spain. \\ ${ }^{5}$ Regional Centre of Advanced Technologies and Materials, Faculty of Science, Palacký University in \\ Olomouc, 17. Listopadu 1192/12, 77146 Olomouc, Czech Republic.
}

*Corresponding author.

E-mail address: Josep.a.benito@upc.edu

Tel. +34-934010946, Fax.+34-934010706

Materials Science Department, Pavelló E. ETSEIB.

Av. Diagonal, 647.

08028 Barcelona

Spain 


\begin{abstract}
Nanoscale Zero Valent Iron (nZVI) represents a promising material for subsurface water remediation technology. However, dry, bare nZVI particles are highly reactive, being pyrophoric when they are in contact with air. The current trends of nZVI manufacturing lead to the surface passivation of dry nZVI particles with a thin oxide layer, which entails a decrease in their reactivity. In this work an activation procedure to recover the reactivity of air-stable nZVI particles is presented. The method consists of exposing nZVI to water for 36 hours just before the reaction with the pollutants. To assess the increase in nZVI reactivity based on the activation procedure, three types of nZVI particles with different oxide shell thicknesses have been tested for Cr(VI) removal. The two types of air-stable nZVI particles with an oxide shell thickness of around 3.4 and $6.5 \mathrm{~nm}$ increased their reactivity by a factor of 4.7 and 3.4 after activation, respectively. However, the pyrophoric nZVI particles displayed no significant improvement in reactivity. The improvement in reactivity is related mainly to the degradation of the oxide shell, which enhances electron transfer and leads secondarily to an increase in the specific surface area of the nZVI after the activation process. In order to validate the activation process, additional tests with selected chlorinated compounds demonstrated an increase in the degradation rate by activated nZVI particles.
\end{abstract}

\title{
Keywords:
}

Nanoscale zero-valent iron (nZVI); reactivity; Cr(VI) remediation; aging; oxide layer. 
Graphical abstract

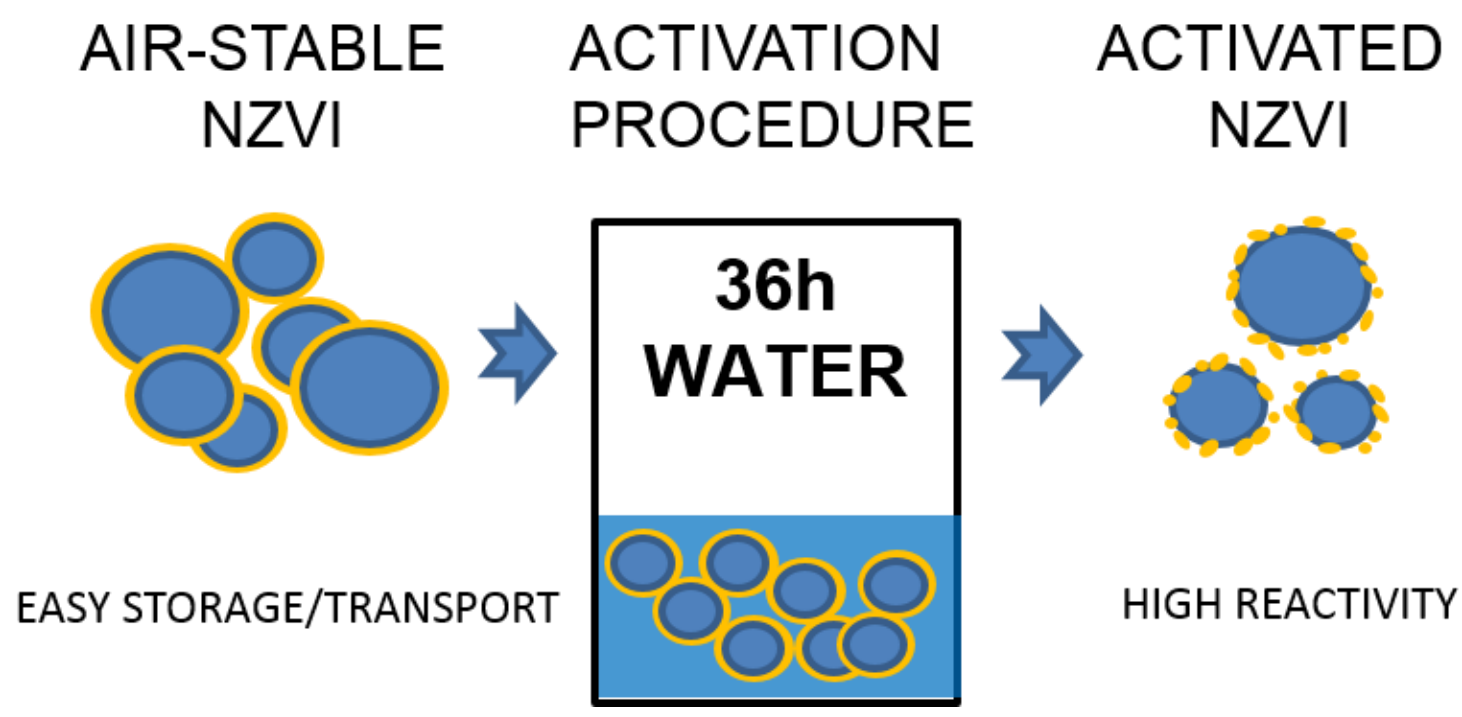




\section{Introduction}

Nanoscale Zero Valent Iron (nZVI) particles have been extensively studied and used to degrade a wide range of contaminants, such as: chlorinated organic and nitroaromatic compounds [1]. Besides organic (halogenated) compounds, nZVI can reduce and/or immobilize harmful metals and metalloids [2,3] and other ions: $\mathrm{PO}_{4}{ }^{3-} \mathrm{NO}_{3}^{-}, \mathrm{NO}_{2}^{-}$[4]. Depending on the nature of the contaminant, there are many proposed mechanisms and pathways of iron action: reduction, adsorption, reduction and adsorption, adsorption and precipitation or oxidation [5,6]. It seems clear that the chemical energy is mandatorily supplied by iron corrosion [7]:

$$
2 \mathrm{Fe}_{(s)}^{0}+2 \mathrm{H}_{2} \mathrm{O}_{(l)} \rightarrow 2 \mathrm{Fe}^{2+}+\mathrm{H}_{2(g)}+2 \mathrm{OH}_{(a q)}^{-} E^{0}=-0.39 \mathrm{VEq} \cdot 1
$$

One of the most important features of nZVI is its high specific surface area, boosting its reactivity by several orders of magnitude compared to micrometric ZVI, which results in faster degradation rates of pollutants [8]. It is geometrically demonstrable that particles with a $d$ of $0.5 \mathrm{~mm}$ and $50 \mathrm{~nm}$ have a specific surface area of 1.5 and $15,250 \mathrm{~m}^{2} \cdot \mathrm{kg}^{-1}$, respectively [9]. The increased reactivity of nanosized ZVI presents new challenges at different levels, among which are the possible environmental toxicology and pyrophoricity [10]. With regard to the second point, dry, bare nZVI particles undergo a fast but not explosive exothermic reaction when exposed to the free air-atmosphere [11]. This behaviour entails a handling, safety and logistic problem. Many different approaches have been adopted to desensitize nZVI [12]. The two most common commercial methods are faced with important drawbacks: (I) Transport in a water-slurry form could partially solve safety problems but implies an increase in shipping costs and a loss of reactivity caused by aging [13], (II) Surface passivation of iron powder by the formation of an oxide shell allows storage in air and lower transportation costs but also significantly decreases the reactivity of the product.

Surface passivation is typically performed by leaving the free atmosphere become slowly and progressively in contact with pristine particles. As a result of this process, a superficial and compact 
oxide layer is generated giving long-term air stability of nZVI [11,14]. The thickness of the oxide shell ranges from 1 to $25 \mathrm{~nm}$ depending on the oxidation conditions, and this thickness is nearly independent of the diameter of the nanoparticles [15]. The nature of this oxide shell is being extensively studied since it hinders the electron flow from the metallic iron [16]. As a result, it has been reported that the increase in shell thickness negatively affects the reactivity of nZVI $[17,18]$. It is therefore important to develop an "activation" method able to restore the reactivity of the particles immediately before its use. Because the formation of the oxide shell is the main parameter responsible for the loss in reactivity [16-18], the activation process should be capable of partial or total removal of the oxide shell in an easy way and in a short period of time.

Up to now, the majority of activation processes of nZVI particles described in literature are more focused on prevention of particle agglomeration or increase in their mobility than on removal of the oxide shell. The use of surfactants or polyelectrolyte polymers to promote colloidal stability is related to the first point [7]. The use of porous materials that support the nZVI particles is also based in the first point, but differing results are reported. In some cases, a decrease of reaction rates have been described due to an increase of the mass transfer resistance [19-21] whereas different studies with mesoporous silica and silica-carbon have shown an increase of $\mathrm{Cr}(\mathrm{VI})$ removal related to a large surface area and some protection against oxidation of nZVI particles [22,23]. Another process that has been investigated is the use of ultrasound. On the one hand, the use of ultrasound improve the dispersion of nZVI and consequently there is an increase of reactivity [24]. In addition, it has also been pointed out that if nZVI are coupled with ultrasound the $\mathrm{Cr}(\mathrm{VI})$ removal efficiency increases significantly [19]. This improvement, apart from the known increase of dispersion, is related to a partial breaking of oxide layer and the increase of reactive sites for $\mathrm{Cr}(\mathrm{VI})$ removal. However, it seems difficult to implement this method in subsurface water remediation processes. 
Alternatively, the known reactivity of iron with water could be used as an activation process. On the one hand it has been clearly demonstrated that long-term water exposure decreases the reactivity of nZVI against a wide range of pollutants due to the growing of the oxide/hydroxide shell $[11,13,18,25$ 29], which leads to a passivation of the particles and it is commonly known as water aging [30]. However, there are certain disparities about the effect on the reactivity at short immersion times. An increase in reactivity after 1-2 days of water immersion has been reported for carbon tetrachloride, trichloroethane and 1,1,1,2-tetrachloroethane [18,28,31], but other studies have shown little changes on reactivity during the first days of aging $[13,32]$. In the cases in which an increase of reactivity was detected, different mechanisms were proposed to explain reactivity recovery: (I) The dissolution of the anionic hydroxo species from a spontaneously-formed oxide/hydroxide shell, such as $\mathrm{Fe}(\mathrm{OH})_{\mathrm{y}}{ }^{2-\mathrm{y}}$ and $\mathrm{Fe}(\mathrm{OH})_{\mathrm{x}}{ }^{3-\mathrm{x}}$ known to be soluble and unstable in alkaline media [11]. This process is supported by evidence of the formation of new iron oxide particles in the vicinity of the nZVI particles [11,27,28]. (II) The volumetric expansion of the nZVI core and the intermediate oxides formed during corrosion, which leads the oxide layers to flake off and expose metallic iron to the contaminants [18,31]. The expansion of the corrosion products is being studied due to expected clogging problems in the aquifer matrix during nZVI treatment [33]. In general, theoretical calculations for the different iron oxides formed in nZVI reactions show that the volume of oxides is 2-4 times greater than the volume of iron, which demonstrates a pronounced change in shell volume [34,35].

Because of this lack of definition, the aim of this work is to introduce an activation process to recover the reactivity of air stable nZVI and to describe the main mechanisms of this activation. Three types of nZVI particles, differing in the oxide shell thickness, were selected and subjected to an activation process based on their aging in water in the form of a dense nZVI slurry over a short period of time. The particles were characterized by transmission electron microscopy (TEM), scanning electron microscopy (SEM), and X-ray diffraction (XRD) before and after the activation process. In addition, 
the specific surface area (SSA), the particle size distribution and the $\mathrm{Fe}(0)$ content were determined. The reduction of hexavalent chromium has been chosen as a simple method of evaluating changes in nZVI reactivity after the activation process since the reduction of $\mathrm{Cr}(\mathrm{VI})$ to trivalent chromium is a common mitigation approach in contaminated waters where nZVI is widely studied as a remedial method in this case. Additional tests for degradation of chlorinated compounds have been included to demonstrate the ability of the nZVI activation process to be applicable also for efficient removal of organic pollutants.

\section{Materials and methods}

\subsection{Iron nanoparticles and suspensions}

Iron nanoparticles with a different thickness of shielding oxide layer and $\mathrm{Fe}(0)$ to $\mathrm{Fe}$-oxide ratio (labelled here as 25P, STAR 197 and STAR 400) were prepared according to a previously published procedure $[18,36]$. These nZVI particles were obtained by the thermal reduction of Fe oxides by $\mathrm{H}_{2}$ at high temperature. Samples STAR 197 and STAR 400 were surface-stabilized by protective oxide layers of different thicknesses. In contrast, 25P had no tailored surface modification. For this reason, 25P nZVI particles remain pyrophoric whereas both types of STAR nanoparticles are air stable.

To prepare the nZVI slurries, $20 \mathrm{~g}$ of nZVI particles were added to $80 \mathrm{~mL}$ of deionised water, so the final w/w iron to water ratio was 0.25. The non-pyrophoric iron nanoparticles (STAR 197 and 400) were dispersed with the MICCRA D-9 ART Prozess \& Labortechnik GmbH \& Co. KG high-power unit at $11,000 \mathrm{rpm}$, following the sequence: $60 \mathrm{~s}$ on $-60 \mathrm{~s}$ off $-60 \mathrm{~s}$ on. Suspensions of pyrophoric iron (25P) nanoparticles were prepared using a laboratory dispersing unit LD 05 (Nano Iron, s.r.o.) under a nitrogen atmosphere to prevent nZVI oxidation. The $\mathrm{Fe}(0)$ content was determined based on the volume of produced hydrogen gas when iron nanoparticles react with sulphuric acid at a volumetric 
concentration of $60 \%$ added to the nZVI slurry [32]. The volume of evolved hydrogen is directly proportional to the amount of metallic iron. The presence of iron oxides has no effect on the volume of generated hydrogen, although they can slow down the rate of the reaction [13].

\subsection{Activation process}

To enhance the reactivity of surface-passivated nZVI particles prior to their application, a simple activation procedure was investigated. Initially, the evaluation of the time required for a successful activation was carried out. For this purpose, slurries of STAR 197 and STAR 400 nanoparticles were aged for periods of 12, 24, 36, 48 and 72 hours in deionized water at room temperature followed by resuspension and dilution to the final nZVI concentration. Subsequently, batch tests were performed to determine the $\mathrm{Cr}(\mathrm{VI})$ removal capacity evolution with aging time. The experiments were conducted in $250 \mathrm{~mL}$ hermetically-closed glass bottles with an initial $\mathrm{Cr}(\mathrm{VI})$ concentration of $50 \mathrm{mg} \cdot \mathrm{L}^{-1}$ prepared from dried potassium chromate $\left(\mathrm{K}_{2} \mathrm{CrO}_{4}\right.$, p.a., AppliChem $\left.\mathrm{GmbH}\right)$. To simulate the ion interference and the ionic strength of real groundwater, tap water with an electric conductivity of $210 \mu \mathrm{S} \cdot \mathrm{cm}^{-1}$ was used (after leaving the tap water exposed to air overnight to eliminate the chlorine content). The residual $\mathrm{Cr}(\mathrm{VI})$ concentration was measured using the colorimetric test EPA METHOD 7196A at 2hours intervals until a reaction time of $24 \mathrm{~h}$. Once the optimal activation time was chosen (36 hours), nZVI slurries for the air-stable (STAR 197 and STAR 400) and pyrophoric (25P) nZVI particles were aged for $36 \mathrm{~h}$ in the same conditions described above.

During the course of the activation process, $\mathrm{pH}$ and oxidation redox potential (ORP) data were logged every 2 minutes (Multi 3430, WTW GmbH). ORP values were normalized to a standard hydrogen electrode (SHE) adding $+209 \mathrm{mV}$ (for $25^{\circ} \mathrm{C}$ ). The activated samples (labelled as "A" samples) were characterized in detail by the procedure described above and compared to un-activated samples (labelled as "UA" samples), which were prepared in the same way but without the 36 hours of aging 
in a concentrated slurry and immediately introduced into the reaction batches. In all cases, activated and un-activated nZVI were dried when necessary under protective atmosphere in a glove box (Jacomex 2P), keeping the oxygen concentration below $5 \mathrm{ppm}$. The dried nZVI particles were stored in vials under argon atmosphere.

\subsection{Reactivity evaluation}

Batch experiments with two types of model contaminants, $\mathrm{Cr}(\mathrm{VI})$ and chlorinated aliphatic hydrocarbons (CAHs), were designed to determine the reactivity of the selected nZVI samples in the un-activated and the activated states. In the case of $\mathrm{Cr}(\mathrm{VI})$ removal, the experiments were conducted in the same conditions described in section 2.2. Seven reaction batches were prepared in the same way for each type of nZVI in both states. To initiate the experiments, a different amount of nZVI suspension was added into each batch to get a final concentration of $0.1,0.25,0.5,2.0,2.5,4.0$ and $8.0 \mathrm{~g} \cdot \mathrm{L}^{-1}$. The solutions were allowed to react for $24 \mathrm{~h}$ without agitation except for a vertical rotation every $60 \mathrm{~s}$ to avoid particles settling down or sticking to the glass walls. The batch $\mathrm{pH}$ was not buffered in order to simulate real conditions, consequently $\mathrm{pH}$ reached values of around 9 in all cases. After the $24 \mathrm{~h}$ reaction time, the $\mathrm{Cr}(\mathrm{VI})$ depletion was quantified using the colorimetric test EPA METHOD 7196A. ORP and $\mathrm{pH}$ values were also determined following the same procedures as described above. The 24 h reaction time was chosen since preliminary $\mathrm{Cr}(\mathrm{VI})$ batch tests described in section 2.2 showed that $\mathrm{Cr}(\mathrm{VI})$ depletion mainly took place within the first $2 \mathrm{~h}$. Finally, it is important to note that selected batches were periodically analysed during a 2-month period.

Additional tests with chlorinated hydrocarbons $(\mathrm{CAH})$ were carried out to verify the recovery of reactivity after activation process also with these pollutants. In this case, the experiments were performed only with STAR 197 particles in both the un-activated and activated state. This was because A STAR 197 showed a clearly better Cr(VI) removal capacity than A STAR 400 and therefore A STAR 
197 seems a more promising material for water remediation processes. In these tests, the batch reactors contained real polluted water from an industrial site to imitate real conditions. The physicochemical characterization of this water revealed a $\mathrm{pH}$ of 8.4 , an ORP of $+30 \mathrm{mv}$ and an electrical conductivity of $518 \mu \mathrm{S} \cdot \mathrm{cm}^{-1}$. In addition, the presence of CAH pollutants nitrate and sulphate with a concentration of $20.7 \mathrm{mg} \cdot \mathrm{L}^{-1}$ and $45 \mathrm{mg} \cdot \mathrm{L}^{-1}$, respectively, was detected. The particular amount of $\mathrm{nZVI}$ suspension was added into each batch to get a final concentration of $2.9 \mathrm{~g} \cdot \mathrm{L}^{-1}$ of $\mathrm{nZVI}$. Due to the slower degradation rates of $\mathrm{CAH}$ compared to $\mathrm{Cr}(\mathrm{VI})$, the batches were vertically rotated every $60 \mathrm{~s}$ for 10 days. After the reaction time, the presence of the different chlorinated species was determined by sampling the batch water phase and analysed by GC-MS (CP-3800 coupled to Saturn 2200 MS, Varian USA).

\subsection{Nanoparticle characterization}

The BET specific surface area (SSA) was determined from $\mathrm{N}_{2}$ adsorption using a BET surface area and porosity analyser (ASAP 2020 Micromeritics). Degassing was carried out at a maximum temperature of $100{ }^{\circ} \mathrm{C}$. In addition, the particle size distribution was determined by the laser diffraction technique using a particle size analyser (Beckman coulter LS 13 320) to investigate the degree of agglomeration. The particles were suspended in water and sonicated for ten minutes before each measurement.

For electron microscopy characterization, samples were prepared in a glove box under a nitrogen atmosphere with air locks (Jacomex 2P), keeping the oxygen concentration below $5 \mathrm{ppm}$. The samples were suspended by mixing vigorously in absolute ethanol. For the SEM studies (Gemini ultra plus, Zeiss) the samples were deposited and left to evaporate on standard SEM discs. For the TEM studies (Philips CM30, operating at $300 \mathrm{kV}$ ) a droplet was placed on a 300 copper mesh grid with a supporting film made of holey carbon (S147-3, Agar Scientific). Pyrophoric samples were transferred to the 
microscope using a liquid nitrogen flask to avoid any contact with oxygen. Detailed nZVI surface observations were performed using a high-resolution transmission electron microscopy image (HRTEM) FEI Titan 60-300 microscope with an X-FEG type emission gun, operating at $80 \mathrm{kV}$.

X-Ray powder diffraction (XRD) was performed on a q/q Bragg-Brentano powder diffractometer (X'Pert PRO MPD, PANalytical) using $\mathrm{Cu}-K \alpha$ radiation. Continuous scans from 12 to $120^{\circ} 2 \theta$ were collected with a step size of $0.017^{\circ}$ and a scan speed of $3.4 \cdot 10^{-3}{ }^{\circ} \cdot \mathrm{min}^{-1}$. The surface characteristics of nZVI particles before and after activation were determined by X-ray photoelectron spectroscopy (XPS)

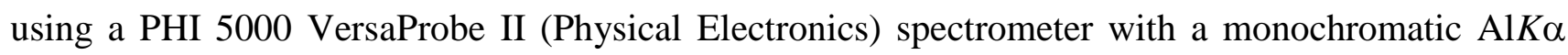
source $(15 \mathrm{kV}, 50 \mathrm{~W}$ and photon energy of $1486.7 \mathrm{eV})$. The spectra were measured in the vacuum of $1.1 \cdot 10^{-7} \mathrm{~Pa}$ at the room temperature of $21^{\circ} \mathrm{C}$. High resolution $\mathrm{Fe} 2 \mathrm{p} 3$ spectra were acquired by setting the pass energy to $23.500 \mathrm{eV}$ and the step size to $0.200 \mathrm{eV}$. For all measurements was used dual beam charge compensation. The XPS spectra were evaluated using the MultiPak (Ulvac - PHI, Inc.) software. All binding energy (BE) values were referenced to the adventitious $\mathrm{C} 1 \mathrm{~s}$ peak at $284.80 \mathrm{eV}$. 


\section{Results and Discussion}

\subsection{Characterization of the initial nanoparticles.}

The as-prepared particles were initially characterized prior to the activation process. The morphology and particle size obtained by FE-SEM for the three types of un-activated nanoparticles are shown in Figure S1. In all cases, the particles had a roughly spherical morphology with a particle size between 50 and $150 \mathrm{~nm}$. The particle size distribution in water solution carried out by laser diffraction techniques showed the presence of aggregates with a size ranging from hundreds of nanometers to some micrometers, especially in the case of the UA STAR 197 and UA STAR 400 samples. A possible explanation for the increase in the size of the aggregates of UA STAR 197 and UA STAR 400 nanoparticles could be related to an increase in the degree of intergrowths between individual particles during the surface passivation process. On the other hand, the specific surface area (BET) was $26.1 \pm$ $0.1 \mathrm{~m}^{2} \cdot \mathrm{g}^{-1}$ for UA 25P nanoparticles, whereas for the surface stabilized samples (UA STAR 197 and UA STAR 400), the surface area decreased to $14.6 \pm 0.1 \mathrm{~m}^{2} \cdot \mathrm{g}^{-1}$ and $16.1 \pm 0.1 \mathrm{~m}^{2} \cdot \mathrm{g}^{-1}$, respectively. A decrease in the specific surface area for shell-modified nZVI particles obtained by similar methods has been already observed by Kim et al [18].

\subsection{Determination of the optimal activation time}

The Figure 1 shows the evolution of the residual $\mathrm{Cr}(\mathrm{VI})$ concentration with activation time for the STAR 197 and STAR 400 nanoparticles. It is clear that there is an increase of the reactivity of both air-stable nanoparticles with water aging, which is in line with some previous studies $[18,28,31]$. This enhancement takes place basically after an activation time of 36-48 hours, and times longer than 48 hours have no significant influence on the reactivity of both air-stable nanoparticles with $\mathrm{Cr}(\mathrm{VI})$. When selecting the optimal activation time for the particles characterization, we considered that this activation process should be applicable in real water remediation processes. Thus, it seems reasonable 
to minimise the activation time while maintain a good improvement in reactivity. Taking this into account, an activation time of 36 hours was chosen for the study.

\subsection{Activation Process}

Figure 2 shows the evolution of $\mathrm{pH}$ and ORP for the three types of suspensions during the activation process: the $\mathrm{pH}$ of all the solutions increased up to the value of around 10 in all cases. This behaviour is consistent with the expected iron corrosion in water according to Eq. 1 or in the presence of oxygen $[3,8]$ and with previously described conditions of high concentrated slurries [13]. On the other hand, the ORP decreased in all cases to below $-500 \mathrm{mV}$. However, there are clear differences in the evolution rates. The UA 25P nanoparticles caused a faster decrease of ORP than the STAR nanoparticles $(\mathrm{pH}$ and ORP were stabilized in less than 4 hours). In the UA STAR 197 suspension, the pH and ORP values reached constant values after 12 hours, and the UA STAR 400 suspension caused even slower changes in $\mathrm{pH}$ and ORP since no stabilization was observed after 36 hours. These differences in the evolution rates are related to the degree of shielding of each type of particle.

\subsection{Characterization of un-activated and activated particles}

Figure 3 presents the TEM images of the three types of nanoparticles in the un-activated and the activated states. The average thickness of the oxide layers, as determined from TEM images, is presented in Table 1. For UA 25P nanoparticles, a very thin oxide layer (around $1.8 \mathrm{~nm}$ ) was observed, which is typical for iron nanoparticles without targeted shell modification [15,27]. The shell-modified nanoparticles showed a uniform layer with a thickness of $3.4 \mathrm{~nm}$ and $6.5 \mathrm{~nm}$ for UA STAR 197 and UA STAR 400, respectively. For the UA 25P nanoparticles the absence of a protective shell promotes the rapid reaction of iron with water or dissolved oxygen. Moreover, UA 25P showed a high specific surface area. These facts explain the fast reaction of UA 25P with water during the activation process as shown in Fig. 2. On the contrary, the shell-modified species showed slower rates than the UA 25P 
nanoparticles. As it has been described elsewhere $[11,18]$, the presence of an oxide layer of about $5 \mathrm{~nm}$ thick implies a clear decrease in reactivity. For UA STAR 197, the stabilization of pH and ORP was clearly delayed with respect to UA 25P, but for UA STAR 400 with an even thicker layer, the reaction with water and oxygen was much slower.

The activated A 25P nanoparticles displayed only slight changes compared to their un-activated counterparts (Fig. 3). However, substantial changes in the oxide shell morphology were found for the A STAR 197 nanoparticles. The surface reveals numerous irregularities caused by partial dissolution of the compact oxide shell. The detail of shell morphology for STAR 197 nanoparticles before and after activation process is shown in Figure 4. This shell detachment has been already observed after one-day reaction with deionized water [18,31]. There was very little evidence of oxides forming during water aging. Some acicular crystals were rarely observed, more frequently in the case of the A STAR 197 sample, which have been previously identified as lepidocrocite [37] or goethite [27], similarly to hexagonal plates of ferrous hydroxide [30] or secondary magnetite/maghemite [11,27]. Another important aspect is that unlike the UA STAR 197 nanoparticles, the activated A STAR 197 nanoparticles showed pyrophoricity when dried in an argon atmosphere and subsequently exposed to air with gentle stirring. This is clear evidence of the successful recovery of nZVI reactivity after the dissolution of the passivating oxide layer. On the other hand, after following the same treatment, the A STAR 400 nanoparticles still contained a uniform shell with just a few discontinuities, but with a clear reduction in the oxide-shell thickness. However, this change was not sufficient to cause pyrophoricity of the dried A STAR 400 samples when exposed to air.

The changes in the $\mathrm{Fe}(0)$ content during the activation process are summarized in Table 2 demonstrating the minimal effect of the activation process on the metallic iron content. This is consistent with the negligible presence of secondary oxides/hydroxides observed by TEM. Similarly, 
highly concentrated slurries $\left(300 \mathrm{ZVI} g \cdot \mathrm{L}^{-1}\right)$ with or without a very low stirring speed together with a high $\mathrm{pH}$ have shown similar behaviour [13,31]. In contrast, if the slurry is diluted, buffered to low $\mathrm{pH}$, with significant stirring speed or with a significant presence of oxygen, the loss of $\mathrm{Fe}(0)$ is much more dramatic at similar aging times $[10,28,37,38]$. These results thus indicate that the nZVI core (i.e., metallic iron) is not significantly affected during the activation process.

Another important aspect is the change in specific surface area (SSA) during the activation process. The results of BET measurements for the three types of nanoparticles in both states (A, UA) are presented in Table 3. It is known that water aging under aerobic conditions, as in the present case, leads to an increase in the SSA [29] and that the SSA could increase during interaction with pollutants $[11,39]$. It must be taken into account that nZVI obtained by the gas reduction process has a different reaction mechanism to nZVI particles obtained by borohydride reduction and a smaller increase in SSA would be expected $[27,38]$. As can be seen, the SSA increased with the activation process in all cases: this increase was small for A $25 \mathrm{P}$, in accordance with a previous study on similarly-prepared nZVI particles [31]. This increase could be attributed to partial iron dissolution followed by overgrowing of nZVI particles by sheet-like iron hydroxides [29,30]. On the other hand, changes in the SSA are much more pronounced in the case of the STAR 197 nanoparticles (see Table 3) due to the high degree of detachment of the oxide shell. In the case of A STAR 400, the increase in SSA was less significant, reflecting less incidences of oxide shell loosening. Another mechanism that can explain an increase in the SSA during the activation process of surface-passivated nZVI particles could be the partial breakdown of aggregates accompanying the dissolution of the oxide shell.

The XRD patterns measured on the nanoparticles in the un-activated and activated state are shown in Figure 5. No significant differences were found between nanoparticles in the un-activated and activated states. This is in line with the fact that very little changes were observed in the $\mathrm{Fe}(0)$ content after the 
activation process. Along with dominant $\alpha$-Fe peaks, the presence of magnetite $\left(\mathrm{Fe}_{3} \mathrm{O}_{4}\right)$ and wüstite (FeO) was also confirmed in all cases without significant variations in the relative composition. The highest oxide content was found in the un-activated and activated STAR 400 nanoparticles, where the relative content was $27 \%$ for magnetite and $15 \%$ for wüstite ( $\alpha$-Fe the rest) based on Rietveld refinement. Both iron oxide phases have been previously identified as possible oxides forming the shell on nZVI prepared by thermal reduction of iron oxide precursors in hydrogen $[6,18,40,41]$. Although XRD patterns of magnetite and maghemite $\left(\gamma-\mathrm{Fe}_{2} \mathrm{O}_{3}\right)$ are very similar [18], the absence of any secondary peaks of maghemite excludes its presence [11].

Finally, the XPS spectra of the surface of activated and un-activated STAR 197 are exposed in Fig. S2. As was pointed out before, no significant differences are observed after activation process since both spectra are very similar. There is not noticeable changes in the signal for $\mathrm{Fe}(0)$, which agrees with the fact that no consumption of iron has been detected during activation. Moreover, no significant variations are observed in the spectral features corresponding to the oxides, which is in agreement with XRD studies where no variation in the composition of the oxide layer was found. This situation is different from other studies in which changes of solvent or the type of nZVI particles cause appreciable changes in the spectral features corresponding to $\mathrm{Fe}(0)$ and Fe-oxides [27,29].

\subsection{Evaluation of particle reactivity}

\section{Reduction of $\mathrm{Cr}(\mathrm{VI})$}

The concentration trends of $\mathrm{Cr}(\mathrm{VI})$ as a function of the nZVI concentration and the calculated $\mathrm{Cr}(\mathrm{VI})$ removal capacities as $\mathrm{mg}$ of $\mathrm{Cr}(\mathrm{VI})$ removed by $\mathrm{g}$ of $\mathrm{Fe}(0)$ for the studied nanoparticles are shown in Figure 6 and Table 4, respectively. Evidently, the Cr(VI) removal capacity varied with the type of nZVI and with the activation state. The highest reaction rate corresponds to the $25 \mathrm{P}$ nanoparticles, with negligible differences between the un-activated and activated particles (i.e., higher for the A 25P 
particles with a removal capacity of $25.8 \mathrm{mg} \mathrm{Cr}(\mathrm{VI}) / \mathrm{g} \mathrm{Fe}(0))$. Even higher reaction rates have been reported in the literature for experiments in which the batches were stirred [42], the solutions were buffered to a lower $\mathrm{pH}[22,28]$ or the nZVI were obtained by the borohydride reduction method [43]. The stabilized nanoparticles in the un-activated state, UA STAR 197 and UA STAR 400, showed very low reactivity compared to the $25 \mathrm{P}$ nanoparticles. However, when activated, these nanoparticles experienced a significant increase in the reaction rate. In the case of A STAR 197, the Cr(VI) removal capacity increased nearly five times more than UA STAR 197 and the values reached slightly above half the reactivity of the $25 \mathrm{P}$ nanoparticles. For A STAR 400 the growth was also considerable since the improvement in reactivity over three times more than for UA STAR 400.

In full accordance with the activation process described in Section 3.3, these differences in reactivity can be explained mainly by the nature of the oxide layer of the un-activated samples and the changes observed in this oxide shell with the activation process. The main removal mechanism of $\mathrm{Cr}(\mathrm{VI})$ is the reduction to $\mathrm{Cr}$ (III) [43] and Eq. 2 illustrates the reduction reaction [44]:

$$
\mathrm{Fe}_{(\mathrm{s})}^{0}+\mathrm{CrO}_{4(\mathrm{aq})}^{2-}+4 \mathrm{H}_{2} \mathrm{O}_{(\mathrm{l})} \rightarrow \mathrm{Fe}(\mathrm{OH})_{3(\mathrm{~s})}+\mathrm{Cr}(\mathrm{OH})_{3(\mathrm{~s})}+2 \mathrm{OH}^{-} \text {Eq. } 2
$$

In this process, the transfer of electrons from $\mathrm{Fe}(0)$ (i.e., from the core of $\mathrm{nZVI}$ ) to the outer surface is a crucial point and it can be produced basically through defects in the oxide layer or via the oxide conduction band [3]. Therefore, the morphology and thickness of the oxide layer both play a key role. On the one hand, irregularities in the oxide layer such as pinholes, detached zones, etc., would promote reaction sites and enhance reactivity. On the other hand, the thickening of the uniform oxide layer would reduce reactivity. Numerous studies suggest that a thickness of around $5 \mathrm{~nm}$ prevents reactivity in the air and therefore leads to lower performance in water remediation $[11,18,45]$. 
At this point it is also important to note that although the batches were allowed to react for 24 hours, the reaction mainly took place within the first 2 hours followed by a dramatic decrease in reactivity which persisted for at least 2 months. Since Fe(0) was not completely consumed, such sudden retardation of reactivity could be directly related to the removal mechanism of $\mathrm{Cr}(\mathrm{VI})$ : the reaction of nZVI with $\mathrm{Cr}(\mathrm{VI})$ in an aqueous solution leads to the reduction of $\mathrm{Cr}(\mathrm{III})$ forming $\mathrm{Cr}$-Fe hydroxides being incorporated into the outer layers of the oxide shell $[43,46]$. At a $\mathrm{pH}$ of above 8 , the reaction with water slows down, and $\mathrm{CrO}_{4}{ }^{2-}$ receive the electrons from $\mathrm{Fe}(0)$ and the precipitation of $\mathrm{Cr}-\mathrm{Fe}$ compounds at the reaction sites creates a passive layer that hinders further $\mathrm{Cr}(\mathrm{VI})$ reduction [28]. In order to simulate real groundwater conditions, the batch $\mathrm{pH}$ was not buffered and therefore the $\mathrm{pH}$ reached a value of $\approx 9$. This condition allows the formation of a passivation layer and could explain the observed sudden drop in nZVI reactivity $[25,43]$. Thus, it can be deduced that the removal capacity of any type of nZVI will depend mainly on the initial sites disposed to electron transfer, either by defects or by zones of thin oxide layers, which allow higher conductivity. In this sense, the specific surface area will also play a significant role allowing more reduction sites prior to passivation.

Considering the above arguments, we will now discuss the reactivity of nZVI with various extents of surface passivation. In the case of the UA 25P nanoparticles with a very thin non-uniform oxide layer (Fig. 3) and with a high SSA, one could expect that the electrons move easily outwards by the oxide conduction band or due to the great number of defect points in the oxide layer [47]. This is then reflected in the high reaction rate. For UA STAR 197 and UA STAR 400 nanoparticles, the drop in the Cr(VI) removal capacity can be linked to a thicker oxide layer (Fig. 3 and 4) and the lower specific surface area. The differences in thickness of the oxide shell between both types of nZVI seem to have a minor effect on reactivity. 
The increase in nZVI reactivity against some pollutants after aging in water for 1-2 days is related to the removal of oxide layer [18,25,28,31], either by dissolution $[11,27,28]$ or by detachment $[18,31]$. There is no a clear increase in the removal capacity of the A $25 \mathrm{P}$ nanoparticles compared to the UA 25P nanoparticles because the changes in the oxide layer after the activation process are negligible and are accompanied by just a small increase in the SSA. However, this observation is not in accordance with the results obtained after 1-2 days of aging similar bare nanoparticles in water [31]. In that study, aging led to a large increase in the removal of carbon tetrachlorine. Despite the similarities in synthetic procedure, particle size, $\mathrm{Fe}(0)$ content, SSA and aging conditions, the TEM images of the as-received particles revealed a rather uniform and 4-5 nm thick oxide layer, which indicates that the particles were probably passivated spontaneously during handling.

A completely different development has been observed for the A STAR 197 and A STAR 400 nanoparticles, where a significant improvement in the removal of $\mathrm{Cr}(\mathrm{VI})$ occurred. In the case of $\mathrm{A}$ STAR 197, this increase can be related to the partial removal of the compact shell (Fig. 3 and 4) enhancing electron transfer. In the case of the A STAR 400 nanoparticles, the activation process created less defect points on the surface of the nanoparticle than in the case of the A STAR 197 sample: many places were observed where the oxide shell remains uniform (Fig. 3), although with a reduction in thickness. This helps to explain the lower increase in the Cr(VI) removal capacity of the A STAR 400 nanoparticles.

Finally, the role of the SSA in the enhanced reactivity of A STAR 197 and A STAR 400 should be taken into account. In the work of Sarathy et al. [31] no significant increase in the SSA related to the process of nZVI aging in water was described, and no other references to an increase in the SSA can be found in published works in which nZVI aging in water for short periods of time was studied $[13,18]$. As mentioned above, a partial breakdown of nanoparticle aggregates is considered to be the main 
reason for the increase in the SSA in A STAR 197 and A STAR 400, along with the rise in the number of small fragments from the former oxide layer. The key parameter influencing the improvement of reactivity of the surface stabilized nZVI particles during the activation process is the increase in the density of defects in the oxide shell [48]. Therefore, if the density of defects is constant, the increase of new surfaces is significant for the reactivity and therefore an increase in the SSA would result in an increase in the capacity of $\mathrm{Cr}(\mathrm{VI})$ removal [18]. In this particular case, the increase in the SSA has a minor effect on the overall increase in the nZVI capacity for $\mathrm{Cr}(\mathrm{VI})$ removal. This is elucidated by a comparison of the reactivity of A 25P and A STAR 197 nanoparticles, although both nZVI particles have a comparable SSA the A 25P sample has twice the Cr(VI) removal capacity as A STAR 197.

\section{Removal of CAH}

The results of the reactivity tests of UA STAR 197 and A STAR 197 with different types of chlorinated compounds are shown in Table 5. Following the activation process, there was a significant improvement in the activity against the different CAHs compared to un-activated counterparts. This enhancement in nZVI particles reactivity with a short period of their water aging has also previously been reported for carbon tetrachloride, trichloroethylene and 1,1,1,2-tetrachloroethane [18,28,31], and it is in full accordance with the above-presented reduction of $\mathrm{Cr}(\mathrm{VI})$. These experiments confirm that the described process, employed here for the activation of initially dry, surface-passivated nZVI particles, can be further applied for the effective removal of a wide range of different pollutants that are usually treatable by nZVI particles.

\section{Conclusions}


The thick and compact oxide shield of surface-passivated nZVI particles significantly decreases their performance in the reduction of $\mathrm{Cr}(\mathrm{VI})$ compared to non-stabilized nZVI particles. The introduction of a simple activation process consisting of an aging of dense nZVI slurry in water for less than 48 hours led to a partial recovery of the nZVI reactivity. The increase in the reactivity is explained by partial dissolution of the oxide layers, which allows an improvement in the transfer of electrons from the inside of the particles to the surface, as well as a partial breakdown of aggregates leading to an increase in the SSA. The recovery of reactivity is higher the thinner the initial thickness of the oxide shell, since it seems to be more favourable for breaking the uniform oxide shell and creating a high density of defects.

At the same time, the activation process does not decrease $\mathrm{Fe}(0)$ content. The clear improvement in the degradation of chlorinated organic compounds after the activation process confirms that the proposed procedure is suitable for nZVI-based treatment of a wide range of contaminants. Therefore, the described activation process is an important new procedure, which can be applied before the injection of nZVI into the treated subsurface area and could represent an easy way of increasing the effectiveness of the remediation and simplifying the overall handling of nZVI.

\section{Acknowledgements}

The present research work was funded by the EU-project NANOREM (Taking Nanotechnological Remediation Processes from Lab Scale to End User Applications for the Restoration of a Clean Environment, NMP.2012.1.2-1 FP7 - Grant Agreement Nr. 309517) and by the Ministry of Education, Youth and Sports of the Czech Republic (projects LO1305 and CZ.1.05/2.1.00/01.0005). D. Ribas is supported by the Spanish Ministerio de Economía y Competitividad, in the framework of the project (Ref. CGL2011-29975-C04-03) and FPI grant (ref. BES-2012-052327). The authors also acknowledge 
the assistance provided by the research infrastructure NanoEnviCz, supported by the ministry of education, Youth and Sports of the Czech Republic under project No. LM2015073. We would also like to thank Petr Slovak for performing the supporting laboratory experiments and Martin Petr for XPS measurement. 


\section{References}

[1] F.Fu, D.D. Dionysiou, H. Liu, The use of zero-valent iron for groundwater remediation and wastewater treatment: A review, J. of Hazard. Mater. 267 (2014) 194-205.

[2] T. Almeelbi, A. Bezbaruah, Aqueous phosphate removal using nanoscale zero-valent iron, J. Nanopart. Res. 14 (2012) 900-914.

[3] D. O'Carroll,B. Sleep, M. Krol, H. Boparai, C. Kocur, Nanoscale zero valent iron and bimetallic particles for contaminated site remediation, Adv. Water Resour. 51 (2013) 104-122.

[4] K-S. Lin, N.B. Chang, T.D. Chuang, Fine structure characterization of zero-valent iron nanoparticles for decontamination of nitrites and nitrates in wastewater and groundwater, Sci. Technol. Adv. Mater. 9 (2008), 9 (2), 025015 .

[5] S.C.N. Tang, I.M.C. Lo, Magnetic nanoparticles: Essential factors for sustainable environmental applications, Water Res. 47 (2013) 2613-2632.

[6] Y. Ji, Ions removal by iron nanoparticles: A study on solid-water interface with zeta potential. Colloids Surf. A Physicochem. Eng. Asp. 44 (2014) 1-8.

[7] R.A. Crane, T.B. Scott, Nanoscale zero-valent iron: Future prospects for an emerging water treatment technology. J. Hazard. Mater. 211-212 (2012) 112-125.

[8] W.X. Zhang, Nanoscale iron particles for environmental remediation: An overview. J. of Nanopart. Res. 5 (2003) 323-332.

[9] C. Macé, S. Desrocher, F. Gheorghiu, A. Kane, M. Pupeza, M. Cernik, P. Kvapil, R. Venkatakrishnan, W. Zhang, Nanotechnology and groundwater remediation: A step forward in technology understanding. Remediat. J. 16 (2006) 23-33.

[10] K.D. Grieger, A. Fjordbøge, N.B. Hartmann, E. Eriksson,P.L. Bjerg, A. Baun, Environmental benefits and risks of zero-valent iron nanoparticles (nZVI) for in situ remediation: Risk mitigation or trade-off?, J. Contam. Hydrol. 118 (2010) 165-183.

[11] K. Sohn, S.W. Kang, S. Ahn, M. Woo, S.K. Yang, Fe(0) nanoparticles for nitrate reduction: Stability, reactivity, and transformation, Environ. Sci. Technol. 40 (2006) 5514-5519.

[12] A. Tiehm, S. Kraßnitzer, Y. Koltypin A. Gedanken, Chloroethene dehalogenation with ultrasonically produced air-stable nano iron, Ultrason. Sonochem. 16 (2009) 617-621.

[13] Y. Liu, G.V. Lowry, Effect of particle age (Fe0 content) and solution pH on NZVI reactivity: $\mathrm{H} 2$ evolution and TCE dechlorination, Environ. Sci. Technol. 40 (2006) 6085-6090.

[14] E.A. Shafranovsky, Y.I. Petrov, Aerosol Fe nanoparticles with the passivating oxide shell, J. Nanopart. Res. 6 (2004) 71-90.

[15] J.E. Martin, A. Herzing, W. Yan, X. Li, B.E. Koel, C.J. Kiely, W. Zhang, Determination of the oxide layer thickness in core-shell zerovalent iron nanoparticles. Langmuir 24 (2008) 4329-4334.

[16] L. Signorini, L. Pasquini, L. Savini, R. Carboni, F. Boscherini, E. Bonetti, A. Giglia, M. Pedio, N. Mahne, S. Nannarone, Size-dependent oxidation in iron/iron oxide core-shell nanoparticles, Phys. Rev. B, 68 (2003) 18.

[17] Y. Liu, H. Choi, D. Dionysiou, G.V. Lowry, Trichloroethene hydrodechlorination in water by highly disordered monometallic nanoiron, Chem. Mater. 17 (2005) 5315-5322. 
[18] H.S. Kim, J.Y. Ahn, K.Y. Hwang, I.L.K. Kim, H. Inseong, Atmospherically stable nanoscale zero-valent iron particles formed under controlled air contact: Characteristics and reactivity. Environ. Sci. Technol. 44 (2010) 1760-1766.

[19] X. Zhou, B. Lv, Z. Zhou, W. Li, G. Jing, Evaluation of highly active nanoscale zero-valent iron coupled with ultrasound for chromium(VI) removal, Chem. Eng. J. 281 (2015) 155-163.

[20] L.N. Shi, Y.M. Lin, X. Zhang, Z.L. Chen, Synthesis, characterization and kinetics of bentonite supported nZVI for the removal of Cr(VI) from aqueous solution, Chem. Eng. J. 171 (2011) 612-617.

[21] Y.Y. Zhang, H. Jiang, Y. Zhang, J.F. Xie, The dispersivity-dependent interaction between montmorillonite supported nZVI and Cr(VI) in aqueous solution, Chem. Eng. J. 229 (2013) 412-419.

[22] E. Petala, K. Dimos, A. Douvalis, T. Bakas, J. Tucek, R. Zbořil, M.A. Karakassides, Nanoscale zero-valent iron supported on mesoporous silica: Characterization and reactivity for $\mathrm{Cr}(\mathrm{VI})$ removal from aqueous solution. J. Hazard. Mater. 261 (2013) 295-306.

[23] K. Xiong, Y. Gao, L. Zhou, X. Zhang, Zero-valent iron embedded on the mesoporous silica-carbon for chromium (VI) removal from aqueous solution. Int. J. Nanopart. Res. 18 (2016) 267-274.

[24] F. Liang, J. Fan, Y.H. Guo, M.H. Fan, J.J. Wang, H.Q. Yang, Reduction of nitriteby ultrasound-dispersed nanoscale zero-valent iron particles, Ind. Eng. Chem. Res. 47 (2008) 8550-8554.

[25] Y. Liu, T. Phenrat, G.V. Lowry, Effect of TCE concentration and dissolved groundwater solutes on NZVIpromoted TCE dechlorination and H2 evolution, Environ. Sci. Technol. 41 (2007) 7881-7887.

[26] Z. Xiu, J. Ming, Z. Hui, T. Li, S. Mahendra, G.V. Lowry, P.J.J. Alvarez, Effects of nano-scale zero-valent iron particles on a mixed culture dechlorinating trichloroethylene, Bioresour. Technol. 101 (2010) 1141-1146.

[27] H.S. Kim,T. Kim, J.Y. Ahn, K.Y. Hwang, J.Y. Park, T.T. Lim, I. Hwang, Aging characteristics and reactivity of two types of nanoscale zero-valent iron particles ( $\mathrm{FeBH}$ and $\mathrm{FeH} 2)$ in nitrate reduction, Chem. Eng. J. 197 (2012) 16-23.

[28] Y. Xie, D.M. Cwiertny, Influence of anionic cosolutes and ph on nanoscale zerovalent iron longevity: Time scales and mechanisms of reactivity loss toward 1,1,1,2-tetrachloroethane and $\mathrm{Cr}(\mathrm{VI})$, Environ. Sci. Technol. 46 (2012) 8365-8373.

[29] H. Woo,J. Park, S. Lee, S. Lee, Effects of washing solution and drying condition on reactivity of nano-scale zero valent irons (nZVIs) synthesized by borohydride reduction, Chemosphere 97 (2014) 146-152.

[30] J. Filip, F. Karlický, Z. Marušák, P. Lazar, M. Cernik, M. Otyepka, R. Zbořil, R. Anaerobic reaction of nanoscale zerovalent iron with water: Mechanism and kinetics, J. Phys. Chem. C 118 (2014) 13817-13825.

[31] V. Sarathy, P.G. Tratnyek, J.T. Nurmi, D.R. Baer, J.E. Amonette, C.L. Chun, R.L. Penn, E.J. Reardon, Aging of iron nanoparticles in aqueous solution: Effects on structure and reactivity, J. Phys. Chem. C 112 (2008) 2286-2293.

[32] Y. Liu, S.A. Majetich, R.D. Tilton, D.S. Sholl, G.V. Lowry, TCE dechlorination rates, pathways, and efficiency of nanoscale iron particles with different properties, Environ. Sci. Technol. 39 (2005) 1338-1345.

[33] C. Noubactep, S. Car, R. Crane, Nanoscale metallic iron for environmental remediation: Prospects and limitations. Water. Air. Soil Pollut. 223 (2012) 1363-1382.

[34] U. Schwertmann, R.M. Cornell, Iron oxides in the laboratory: preparation and characterization; Wiley-VCH Verlag, Weinheim, Germany, 2000, pp. 1-12.

[35] R.M. Cornell, U. Schwertmann, The Iron Oxides: Structure, Properties, Reactions, Occurrences and Uses, John Wiley \& Sons: Freising, Germany, 2006, Vol. 39. 
[36] R. Zboril, M. Andrle, F. Oplustil, L. Machala, J. Tucek, J. Filip, Z. Marusak, V.K. Sharma, Treatment of chemical warfare agents by zero-valent iron nanoparticles and ferrate(VI)/(III) composite, J. Hazard. Mater. 211-212 (2012) 126-130.

[37] A. Liu, J. Liu, B. Pan, W. Zhang, Formation of lepidocrocite ( $\gamma-\mathrm{FeOOH})$ from oxidation of nanoscale zerovalent iron (nZVI) in oxygenated water. RSC Adv. 4 (2014) 57377-57382..

[38] A. Liu, J. Liu,W.X. Zhang, Transformation and composition evolution of nanoscale zero valent iron (nZVI) synthesized by borohydride reduction in static water, Chemosphere 119 (2015) 1068-1074.

[39] P. Huang, Z. Ye, W. Xie, Q. Chen, J. Li, Z. Xu, M. Yao, Rapid magnetic removal of aqueous heavy metals and their relevant mechanisms using nanoscale zero valent iron (nZVI) particles, Water Res. 47 (2013) 40504058 .

[40] A. Liu, W. Zhang, Fine structural features of nanoscale zero-valent iron characterized by spherical aberration corrected scanning transmission electron microscopy (Cs-STEM), Analyst 139 (2014) 4512-4518.

[41] J. Soukupova, R. Zboril, I. Medrik, J. Filip, K. Safarova, R. Ledl, M. Mashlan, J. Nosek, M. Cernik, Highly concentrated, reactive and stable dispersion of zero-valent iron nanoparticles: Direct surface modification and site application, Chem. Eng. J. 262 (2015) 813-822.

[42] R.F. Yu, F.H. Chi, W.P. Cheng, J.C. Chang, Application of pH, ORP, and DO monitoring to evaluate chromium (VI) removal from wastewater by the nanoscale zero-valent iron (nZVI) process, Chem. Eng. J. 255 (2014) 568-576.

[43] X.Q. Li, J. Cao, W. Zhang, Stoichiometry of $\mathrm{Cr}(\mathrm{VI})$ immobilization using nanoscale zero valent iron (nZVI): A study with high-resolution X-ray photoelectron spectroscopy (HR-XPS). Ind. Eng. Chem. Res. 47 (2008) 2131-2139.

[44] N. Melitas, O. Chuffe-Moscoso, J. Farrell, Kinetics of soluble chromium removal from contaminated water by zerovalent iron media: Corrosion inhibition and passive oxide effects, Environ. Sci. Technol. 35 (2001) 39483953.

[45] J.T. Nurmi, P.G. Tratnyek, V. Sarathy, D.R. Baer, J.E. Amonette, K. Pecher, C. Wang, J.C. Linehan, D.W. Matson, R.l. Penn, et al., Characterization and Properties of Metallic Iron Nanoparticles: Spectroscopy, Electrochemistry, and Kinetics, Environ. Sci. Technol. 39 (2005) 1221-1230.

[46] M. Kerkar, J. Robinson, A.J. Forty, In situ structural studies of the passive film on iron and iron/chromium alloys using X-ray absorption spectroscopy, Faraday Discuss. Chem. Soc. 89 (1990) 31-40.

[47] X. Li, D.W. Elliott, W. Zhang, Zero-Valent Iron Nanoparticles for Abatement of Environmental Pollutants: Materials and Engineering Aspects. Crit. Rev. Solid State Mater. Sci. 31 (2006) 111-122.

[48] S. Lapuerta, N. Moncoffre, N. Millard-Pinard, H. Jaffrézic, N. Bérerd, D. Crusset, Role of proton irradiation and relative air humidity on iron corrosion. J. Nucl. Mater. 352 (2006) 174-181. 


\section{TABLES AND FIGURES}

Table 1. Mean thickness of the oxide layer in $\mathrm{nm}, 95 \%$ confidence interval, $(n)=$ number of measurements.

\begin{tabular}{lccc}
\hline & 25P & STAR 197 & STAR 400 \\
\hline $\begin{array}{l}\text { Un- } \\
\text { activated }\end{array}$ & $1.8 \pm 1.0(10)$ & $3.4 \pm 1.5(12)$ & $6.5 \pm 1.2(12)$ \\
Activated & Discontinuous & Discontinuous & $4.4 \pm 1.3(12)$ \\
\hline
\end{tabular}

Table 2. Relative $\mathrm{Fe}(0)$ content of the selected iron nanoparticles, before and after activation. Results are expressed in weight percentages.

\begin{tabular}{cccc}
\hline & 25P & $\begin{array}{c}\text { STAR } \\
\mathbf{1 9 7}\end{array}$ & $\begin{array}{c}\text { STAR } \\
\mathbf{4 0 0}\end{array}$ \\
\hline Un-activated & $87 \pm 1$ & $78 \pm 1$ & $57 \pm 1$ \\
Activated & $86 \pm 1$ & $77 \pm 1$ & $57 \pm 1$ \\
\hline
\end{tabular}

Table 3. BET specific surface area of nZVI particles before and after activation. Results are expressed in $\mathrm{m}^{2} \cdot \mathrm{g}^{-1}$.

\begin{tabular}{lc}
\hline & $\mathbf{S S A}\left(\mathbf{m}^{\mathbf{2}} \cdot \mathbf{g}^{-1}\right)$ \\
\hline UA 400 & $16.1 \pm 0.1$ \\
A 400 & $23.4 \pm 0.1$ \\
\hline UA 197 & $14.6 \pm 0.1$ \\
A 197 & $30.0 \pm 0.1$ \\
\hline UA 25P & $26.1 \pm 0.1$ \\
A 25P & $28.7 \pm 0.1$ \\
\hline
\end{tabular}

Table 4. Slope, relative slope increment after the activation process $(\Delta), R^{2}$ of regressions from concentration iron tests and $\mathrm{Cr}(\mathrm{VI})$ removal capacity.

\begin{tabular}{lcccc}
\hline & $\frac{\boldsymbol{\Delta} \mathbf{c} / \mathbf{c}_{\mathbf{0}}}{\boldsymbol{\Delta}[\mathbf{F e}]}$ & $\boldsymbol{\Delta}$ & $\mathbf{R}^{\mathbf{2}}$ & $\frac{\boldsymbol{m} \boldsymbol{g} \boldsymbol{C r}(\boldsymbol{V I})}{\boldsymbol{g} \boldsymbol{F e}(\mathbf{0})}$ \\
\hline STAR 400 UA & -0.048 & & 0.98 & 2.4 \\
STAR 400 A & -0.151 & 3.15 & 0.99 & 7.5 \\
\hline STAR 197 UA & -0.056 & & 0.99 & 2.8 \\
STAR 197 A & -0.263 & 4.70 & 0.99 & 13.2 \\
\hline 25P UA & -0.495 & & 0.99 & 24.8 \\
25PA & -0.516 & 1.04 & 0.99 & 25.8 \\
\hline
\end{tabular}


Table 5. Final concentrations of contaminants in blanks, un-activated and activated batches for STAR 197. TCM Trichloromethane, PCM Tetrachloromethane, cis-DCE cis-1,2-Dichloroethene, TCE Trichloroethylene, PCE Tetrachloroethylene. (n) number of replicates, (n.d.) not detected; 95\% C.I.

\begin{tabular}{lccccc}
\hline & $\begin{array}{c}\text { TCM } \\
\mu \mathrm{g} \cdot \mathrm{L}^{-1}\end{array}$ & $\begin{array}{c}\text { PCM } \\
\mu \mathrm{g} \cdot \mathrm{L}^{-1}\end{array}$ & $\begin{array}{c}\text { cis-DCE } \\
\mu \mathrm{g} \cdot \mathrm{L}^{-1}\end{array}$ & $\begin{array}{c}\text { TCE } \\
\mu \mathrm{g} \cdot \mathrm{L}^{-1}\end{array}$ & $\begin{array}{c}\text { PCE } \\
\mu \mathrm{g} \cdot \mathrm{L}^{-1}\end{array}$ \\
\hline Blank (3) & 553 & 1187 & 276 & 420 & 7308 \\
\hline UA STAR 197 (2) & 492 & 1199 & 254 & 412 & 7820 \\
A STAR 197 (2) & n.d. & n.d. & n.d. & n.d. & 1900 \\
\hline
\end{tabular}




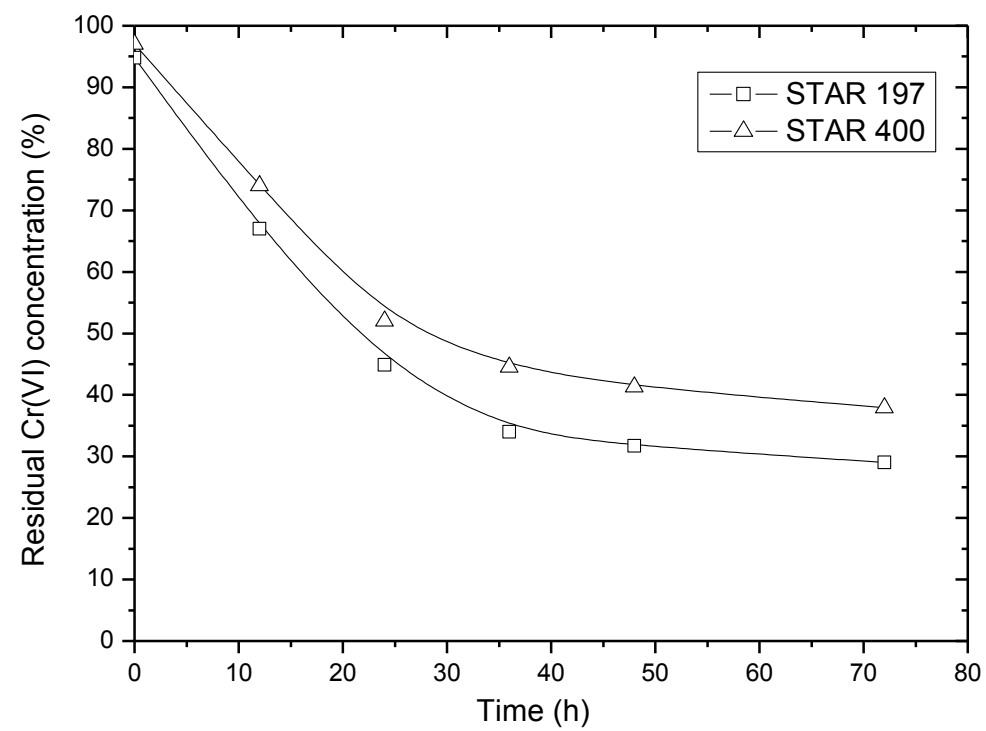

Figure 1. Evolution of the residual Cr(VI) concentration with activation times for STAR 197 and STAR 400 particles. Initial Cr(VI) concentration of $50 \mathrm{mg} \cdot \mathrm{L}^{-1}$ in tap water. 


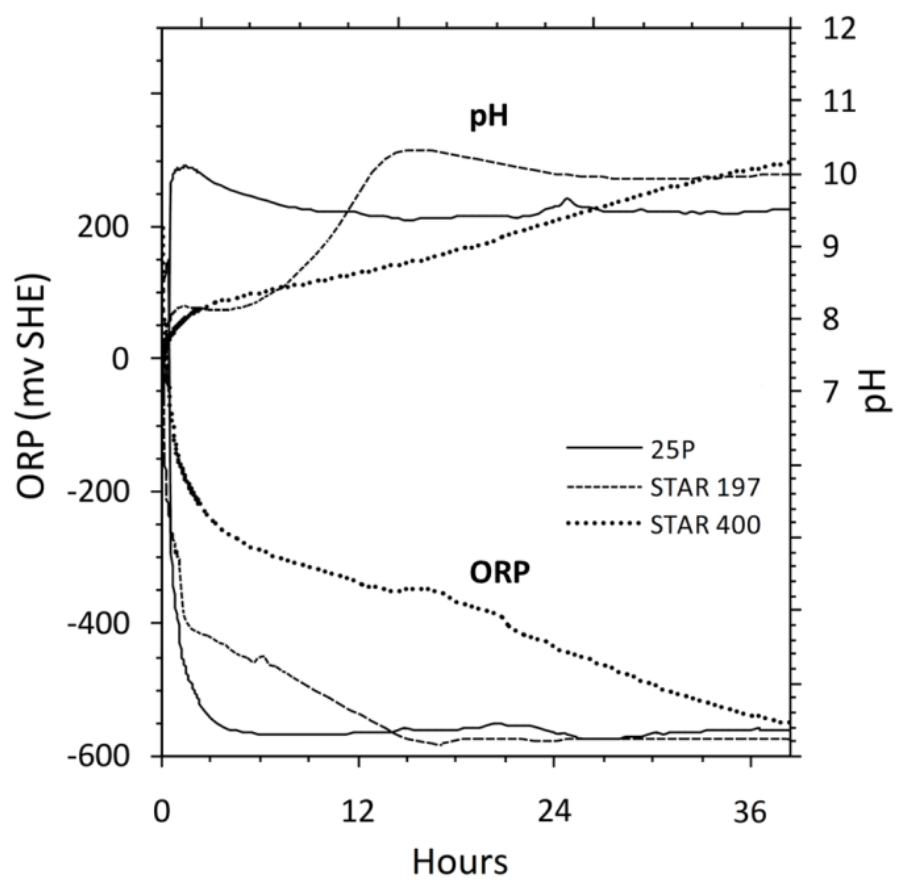

Figure 2. $\mathrm{pH}$ and ORP development during the activation process. Data logged every 2 minutes (Multi 3430, WTW GmbH). ORP values normalized to a standard hydrogen electrode (SHE) adding +209 $\mathrm{mV}$ (for $25^{\circ} \mathrm{C}$ ). 


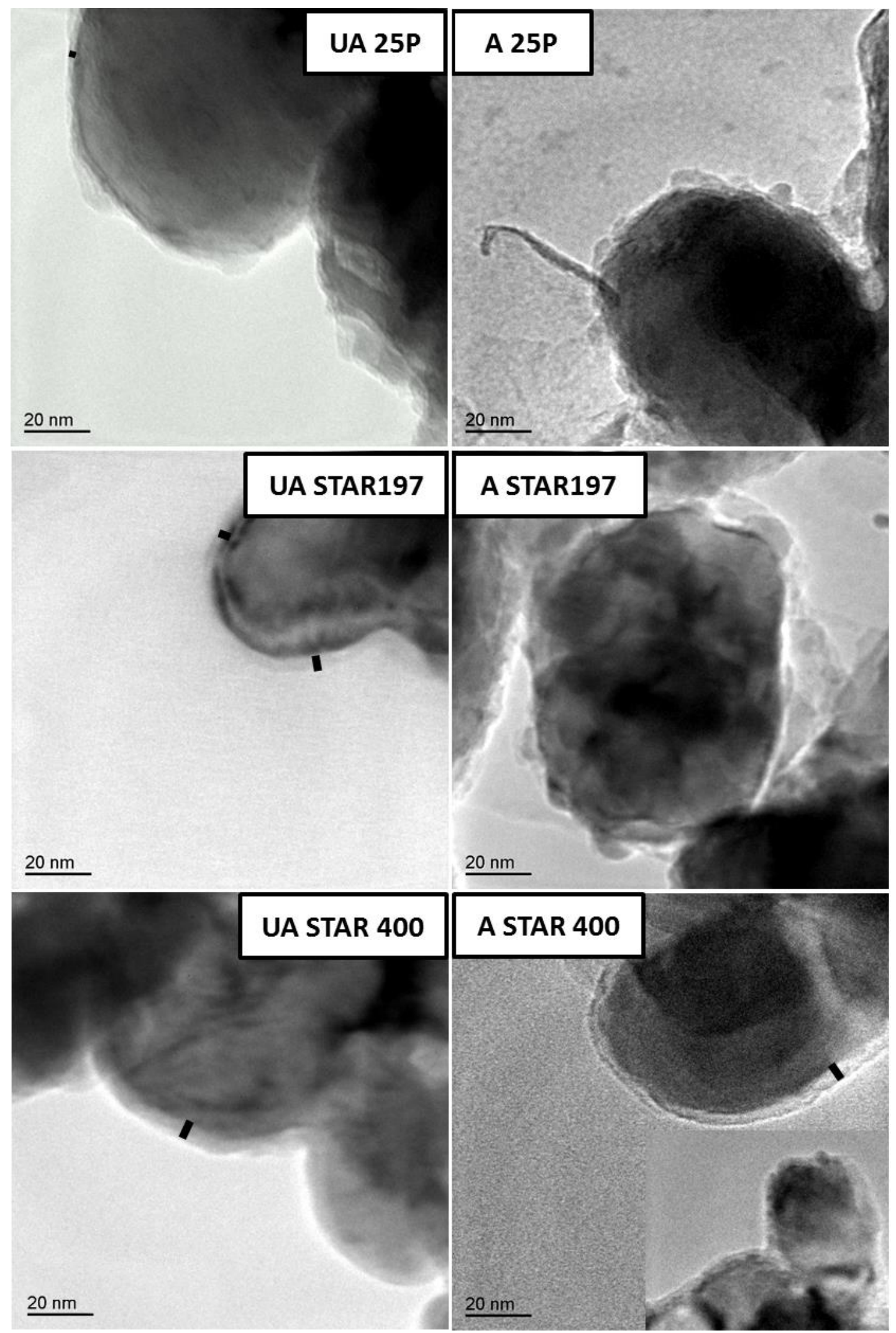

Figure 3. TEM images of the three types of nanoparticles in the un-activated and activated states. The black bars show the thickness of the oxide layer. 


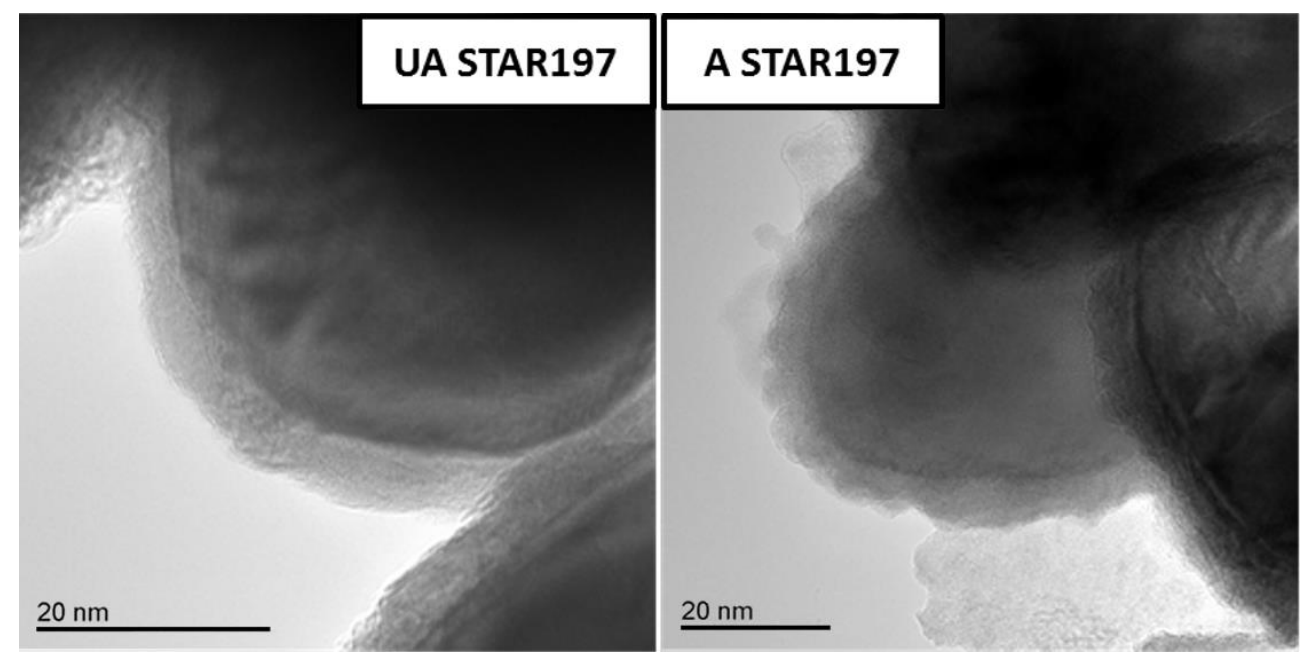

Figure 4. Detail of the surface layer on STAR 197 nanoparticles before (UA STAR 197) and after activation (A STAR 197). 


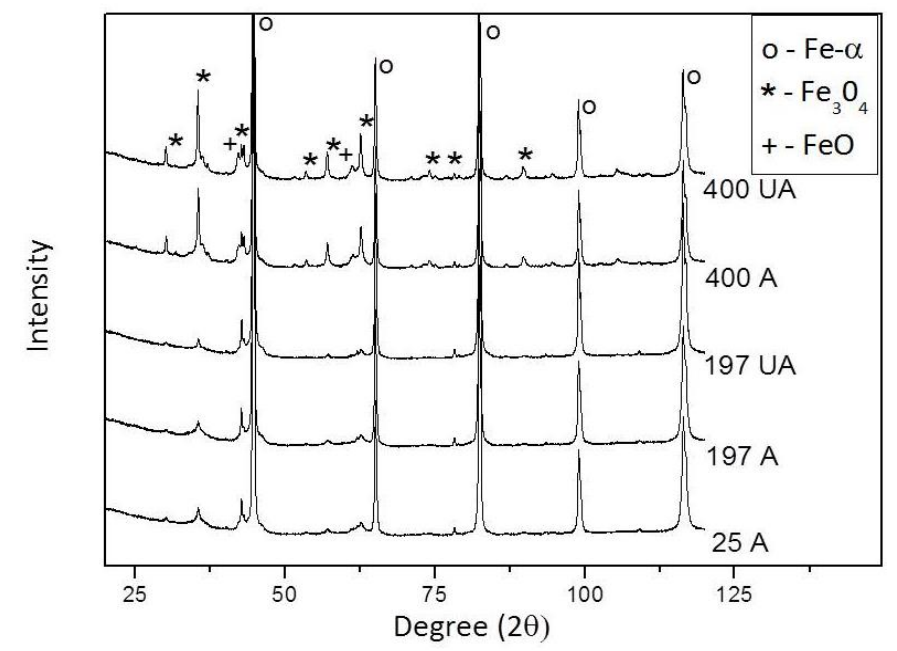

Figure 5. XRD patterns of: UA (Un-activated) and A (Activated) samples.

Step size: $0.017^{\circ}$ and scan speed: $3.4 \cdot 10^{-3}{ }^{\circ} \cdot \mathrm{min}^{-1}$ 


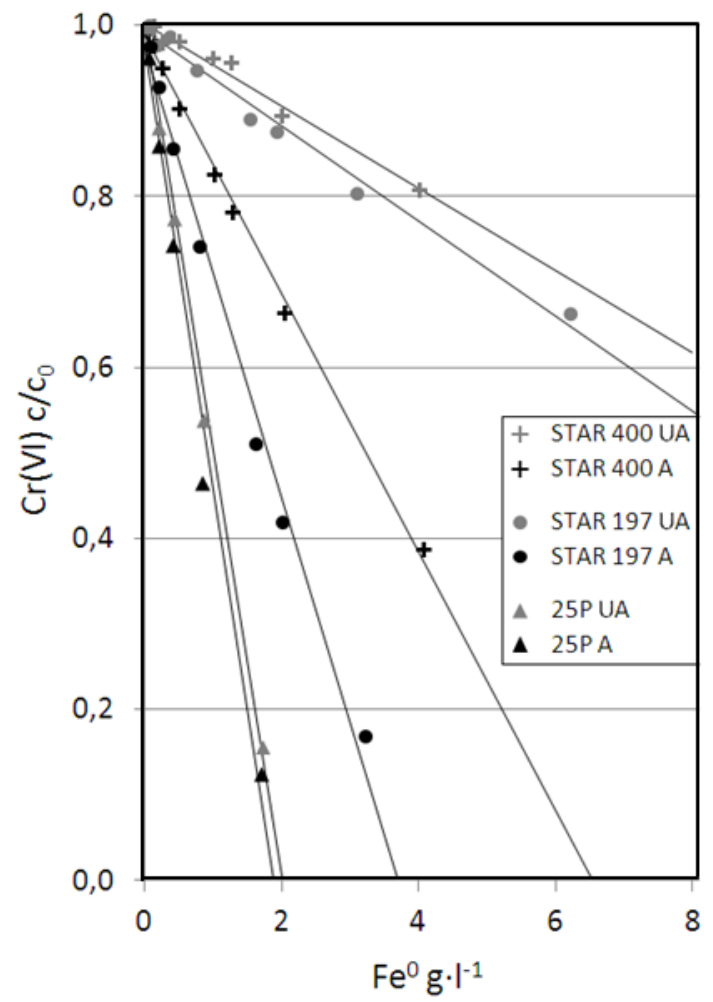

Figure 6. Cr(VI) removal by various concentrations of nZVI particles (STAR 400, STAR 197 and $25 \mathrm{P})$ in the activated and un-activated states. Initial $\mathrm{Cr}(\mathrm{VI})$ concentration of $50 \mathrm{mg} \cdot \mathrm{L}^{-1}$ in tap water. 24 hours reaction time (without stirring). The $\mathrm{pH}$ was not buffered. 


\section{SUPPLEMENTARY MATERIAL}

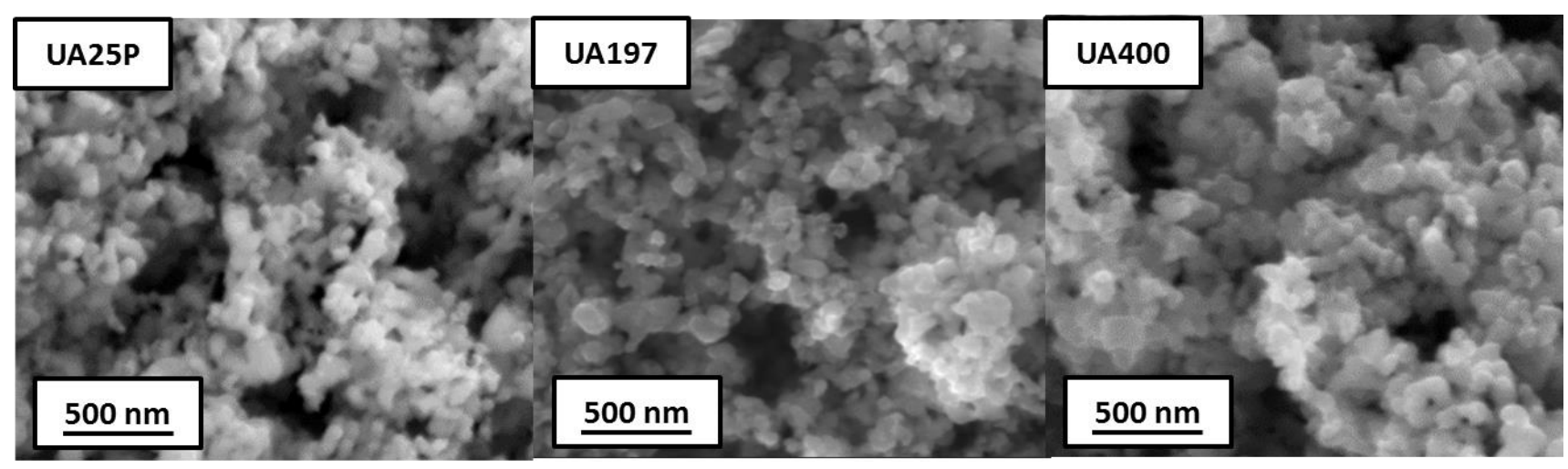

Figure S1. FE-SEM image of the as-received particles in the un-activated state.
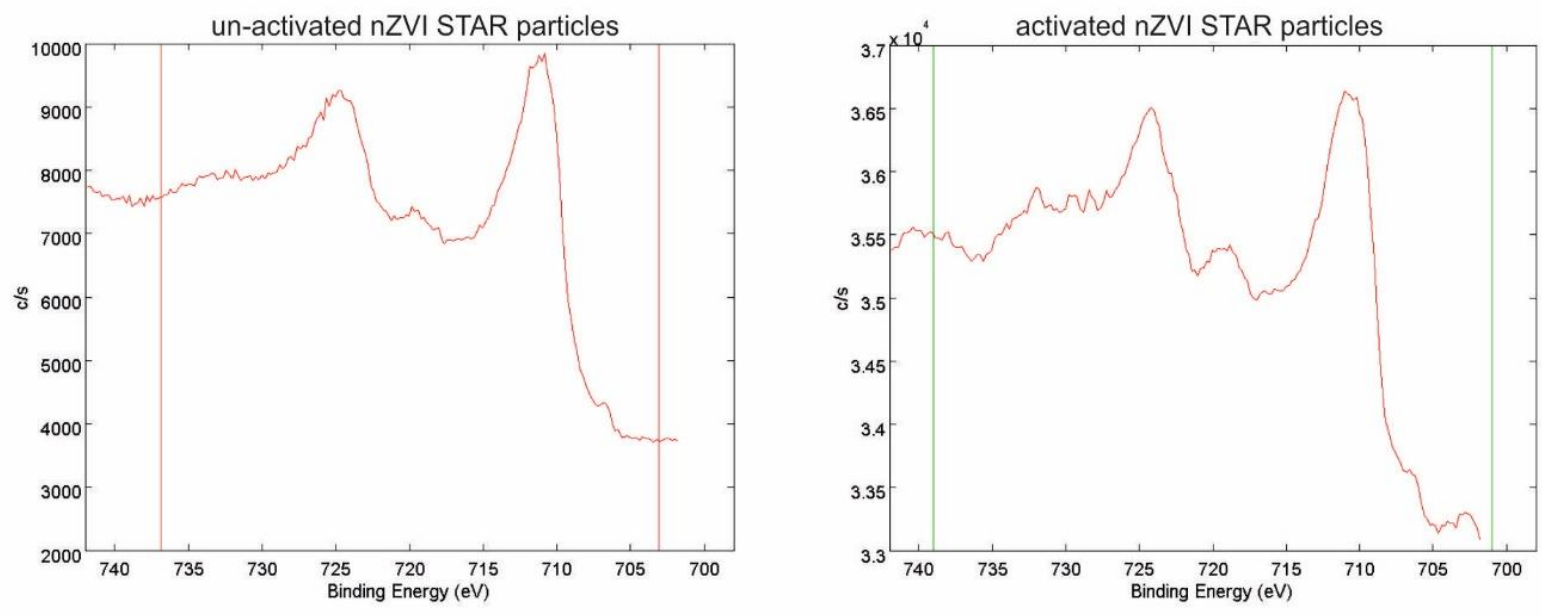

Figure S2. XPS spectra in Fe 2P region for un-activated (left) and activated (right) STAR 197 particles. Measured in the vacuum of $1.1 \cdot 10^{-7} \mathrm{~Pa}$ at $21{ }^{\circ} \mathrm{C}$. Fe $2 \mathrm{p} 3$ spectra acquired by setting the pass energy to $23.500 \mathrm{eV}$ and the step size to $0.200 \mathrm{eV}$. 